\title{
DESARROLLO PREVISIBLE DE LA RELACIÓN ENTRE LA ANTIJURIDICIDAD Y LA CULPABILIDAD
}

\author{
Mauricio Alfredo Rettig Espinoza*
}

\begin{abstract}
RESUMEN
Dos han sido las tendencias que han intentado definir la antijuridicidad penal. La primera concibe la antijuridicidad como lo contrario a derecho, centrando el análisis en la infracción de la norma penal y la segunda sostiene que la antijuridicidad es la lesión o puesta en riesgo del bien jurídico protegido. Aun cuando la segunda postura pareciera baberse impuesto, estableciéndose una clara distinción entre la antijuridicidad y la culpabilidad, la visión de la antijuridicidad como infracción de la norma suma cada vez más adeptos en la actualidad, con lo cual la frontera entre la antijuridicidad y la culpabilidad se hace cada vez más difusa. Lo anterior trae consecuencia para el sistema penal en su conjunto.
\end{abstract}

$$
\text { ANTIJURIDICIDAD - NORMA - BIEN JURÍDICO }
$$

Forseeable development in the connection between illegality and guilt

\begin{abstract}
Two trends have attempted to define penal illegality (actus reus general defences). The first conceives it as what is in opposition to law, and the second trend supports that it's the injury of the legally protected interest. Even though the second stance seems to have prevailed, setting up a clear distinction between illegality and guilt, the view implied in the first trend, that equates it with an infraction of a rule, has currently seen a growing number of supporters, with which the line between both views is more blurred each time. The aforementioned brings consequences to the Criminal Law as a whole.
\end{abstract}

\section{ILLEGALITY (ACTUS REUS GENERAL DEFENCES) - RULE - LEGALLY PROTECTED INTEREST}

* Abogado, Magíster en Derecho, Profesor de Derecho penal y de Derecho procesal penal del Magíster de Derecho penal de la Pontificia Universidad Católica de Valparaíso, Juez del Segundo Tribunal Oral en lo Penal de Santiago, correo electrónico mrettig@pjud.cl

Artículo enviado el 15 de septiembre de 2008 y aceptado para su publicación por el Comité Editorial el 26 de octubre de 2009. 


\section{Concepto de Antijuridicidad}

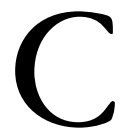

omo se desprende del análisis de la evolución de la dogmática penal, dos han sido las tendencias que han intentado definir la antijuridicidad penal. Una sustentada principalmente por Merkel y luego Binding ${ }^{1}$ que concibe la antijuridicidad como lo contrario a derecho, perspectiva formal del injusto que centra el análisis en la infracción de la norma penal y que constituye un punto de vista derivado de la teoría imperativa de la norma, partidaria de un enfoque instrumental de la norma como medio para intervenir en el proceso decisorio de los destinatarios, dirigiendo su comportamiento hacia los fines prefijados por el derecho mediante mandatos o prohibiciones, razón por la cual deben tenerse en cuenta sus circunstancias. El contenido objetivo de la norma sólo se transforma en preceptivo (en deber) frente a quienes están en condiciones de cumplir lo ordenado (como decía Kant: debe implica puede).

La otra tendencia, sostenida fundamentalmente por Jhering y luego por Von Liszt, ${ }^{2}$ defiende una perspectiva material del injusto, conforme a la cual la antijuridicidad es la lesión o puesta en riesgo del bien jurídico protegido.

${ }^{1}$ Más claramente en su primera etapa.

2 Von Liszt definía el delito como el acto culpable contrario al derecho. Por lo tanto, sostenía que sus elementos eran la acción, la antijuridicidad y la culpabilidad. Así, en cuanto a la acción, decía que el delito es siempre un acto humano y, por tanto, una actuación voluntaria trascendente al mundo exterior; es decir, la causa o no impedimento de un cambio en el mundo exterior. De esta manera, afirma el autor que nunca llegarán a constituir un delito los acontecimientos fortuitos, independientes de la voluntad humana. Respecto de la antijuridicidad, sostenía que el delito es, además, un acto contrario al derecho: es decir, un acto que, contraviniendo, formalmente, a un mandato o prohibición del orden jurídico, implica, materialmente, la lesión o peligro de un bien jurídico. Por último, en lo que dice relación con la culpabilidad, afirmaba que el delito es un acto culpable: es decir, un acto doloso o culposo de un individuo responsable, con lo cual el dolo y la culpa no eran para él sino especies o formas de culpabilidad. Así las cosas, Von Liszt sostiene que el delito se presenta, pues, como un acto apreciado jurídicamente en dos direcciones: en el elemento esencial de contrario al derecho, recae la reprobación sobre el acto; en el elemento característico de culpabilidad, recae sobre el autor. De este modo, el concepto del acto, apreciado por el derecho, se establece como concepto fundamental de la teoría del delito (al respecto ver Liszt, F. V., Tratado de Derecho penal, Valletta Ediciones, Buenos Aires, 2007, pp. 351-352).

A los elementos de la acción, antijuridicidad y culpabilidad, Beling agrega en 1906 el elemento del tipo. El gran aporte de Beling es haber dado un concepto unívoco al vocablo alemán "Tatbestand" entendiéndolo como delito tipo, es decir, como un esquema común para los elementos objetivos descriptivos del delito, naciendo de esta forma el concepto de tipo como una categoría independiente en la estructura de la teoría del delito. Concordando con el viejo principio Nullum crimen, nulla poena sine lege concebido por Feuerbach (al respecto, ver Feuerbach, V., A., Tratado de Derecho penal, Hammurabi, Buenos Aires, 2007, pp. 54-55), Beling plantea que el catalogo de tipos delictivos surge como una reacción del liberalismo del siglo XVIII frente a la inseguridad que planteaba el hecho de que toda acción, antijurídica y culpable, era ya constitutiva de una acción punible, faltando una firme delimitación de las acciones que pudieran considerarse punibles, pudiendo el juez someter a pena toda acción que le desagradara, pretendiéndola antijurídica y pudiendo imponer arbitrariamente una pena grave o leve para toda acción estimada punible. De esta forma, el estrechamiento de las acciones antijurídicas y culpables a determinados tipos delictivos para los cuales se previó una pena concreta y determinada, constituyó una garantía para el individuo frente al poder punitivo del Estado. Así, desde Beling, no hay delito sin tipo legal, bajo la conminación de una pena solo caen aquellas acciones formuladas claramente en especies de delitos definidas por el derecho positivo, escogidas por ser 
Si bien es posible sostener que la segunda postura pareciera haberse impuesto sobre la primera, estableciéndose con ello una clara distinción entre la antijuridicidad y la culpabilidad, es innegable que la visión de la antijuridicidad como infracción de la norma suma cada vez más adeptos en la actualidad, ${ }^{3}$ con lo cual la frontera entre la antijuridicidad y la culpabilidad se hace cada vez más difusa.

Pese a lo dicho, me parece que ambas posiciones no son irreconciliables, es decir, cuando el legislador decide tipificar una conducta como delito lo que está haciendo es precisamente seleccionar determinados bienes jurídicos que merecen ser protegidos por la última razón del sistema jurídico, es decir, por el Derecho penal. Lo anterior vale la pena tenerlo presente, por cuanto aun cuando se entienda la antijuridicidad como la infracción de la norma penal, no por ello debe olvidarse el mandato dirigido al legislador, en el sentido de tipificar como delitos sólo aquellas conductas que infrinjan o pongan en riesgo determinados bienes jurídicos. En efecto, conforme al principio de lesividad (también llamado ofensividad), la reacción penal sólo puede activarse cuando se ha traspasado o puesto en peligro un bien jurídico, quedando excluidas del ámbito del Derecho penal, las meras inmoralidades o las simples contravenciones, ya que mientras no se haya mostrado con claridad que una determinada conducta humana produce efectos socialmente dañosos, debe quedar liberada de la amenaza penal, por cuanto el delito es ante todo lesión del bien jurídico y no una mera violación del deber. ${ }^{4}$ Al respecto, Silva Sánchez sostiene que puede afirmarse que la dañosidad social de la lesión sí es requisito de toda protección jurídica del objeto lesionado. Todo bien, para ser "jurídico", requiere, pues, que los ataques contra el mismo se revelen como trascendentes en la esfera social en un sentido dañoso; si al Derecho en su conjunto le competen funciones de protección social, éste sólo podrá intervenir en casos en que concurra la referida dañosidad social. ${ }^{5}$

Así las cosas, me parece que el contenido de la norma, referido a la protección de bienes jurídicos, debe operar como un límite al ius puniendi y, por lo tanto, no creo que la sola protección de la vigencia de la norma, con prescindencia de su contenido, se

lo suficientemente relevantes para la intervención de la retribución pública, por su importancia valórica. Beling vuelve con toda su fuerza al marco concreto y excluyente del derecho positivo, con lo que abre un camino muy rico y fecundo a la dogmática jurídico-penal, que se extiende hasta hoy. El concepto de tipo penal permitió dar al delito un estricto contenido jurídico positivo. Con ello confirió total autonomía al estudio del derecho penal y echó por tierra la concepción de una ciencia penal conjunta, como la planteada por Liszt, en la que el derecho penal era solo un aspecto íntimamente ligado con las demás disciplinas por el concepto de bien jurídico que los traspasaba. Sin embargo, Beling no rechaza el aporte de las demás ciencias, sino que las somete al control jurídico, el cual tiene sus conceptos ya definidos (al respecto ver Beling, E. V., Esquema de Derecho penal, la doctrina del delito tipo, Depalma, Buenos Aires, 1944, pp. 36-37).

3 Así, por ejemplo, Jakobs, G., Derecho penal, parte general, fundamentos y teoría de la imputación, Editorial Marcial Pons, 1997, p. 419; Kaufmann, A., Dogmática de los delitos de omisión, Marcial Pons, 2006, p. 34; Feijoo Sánchez, B. J., Retribución y prevención general. Un estudio sobre la teoría de la pena y las funciones del derecho penal, B de F, 2007, p. 164.

${ }^{4}$ Roxin, C., Derecho penal, parte general, Civitas, Madrid, pp. 52-53, y Politoff, Matus y Ramírez, Lecciones de Derecho penal chileno, parte general, Editorial Jurídica de Chile, Santiago, 2004, p. 66.

${ }^{5}$ Silva Sánchez, J. M., Aproximación al Derecho penal contemporáneo, Bosch, Barcelona, 1992, p. 276 
justifique, ni mucho menos sea una finalidad por sí sola, al menos en un Estado social y democrático de Derecho. ${ }^{6}$

\section{ANTIJURIDICIDAD COMO INFRACCIÓN DE LA NORMA}

Una norma es una pauta de conducta que tiene por finalidad motivar a los destinatarios en uno o en otro sentido. Así, la norma penal tiene por función motivar a los ciudadanos para que eviten realizar ciertos comportamientos que puedan lesionar o poner en riesgo determinados bienes jurídicos.

Si lo que se quiere es motivar a los destinatarios de la norma penal en un sentido u otro, entonces un sistema de la teoría del delito construido en base a la infracción de la norma penal debiera, para ser coherente, considerar la problemática del destinatario de la norma, acorde con la cual, para que una norma pueda ser infringida es necesario que la conducta que externamente transgrede la norma penal sea realizada por un sujeto dotado de ciertas condiciones que le permitan cumplir el contenido de la norma penal. De esta forma, la norma sólo se dirige a quienes pueden cumplirla, sólo en ocasiones en que puedan cumplirla y sólo con un contenido que pueda ser cumplido. Si ello es así, no tiene sentido afirmar que el inimputable, incapaz de entender el contenido normativo, haya infringido una norma penal, aun cuando externamente exista dicha discrepancia entre la acción del sujeto y el contenido de la norma, es decir, el acto antijurídico del inimputable no niega al derecho, el inimputable no busca hacer prevalecer su voluntad particular por sobre la voluntad general, no pone en riesgo con su actuar, la estabilización de la norma. ${ }^{7}$ Tampoco tiene sentido afirmar la infracción de la norma cuando un

${ }^{6} \mathrm{Ni}$ siquiera en la concepción de la antijuridicidad como violación de las normas de derecho objetivo de Merkel se encuentra ausente la importancia del contenido de la norma. En efecto, según Merkel para que una conducta sea contraria a la norma es preciso que además de la imputabilidad del destinatario concurra como núcleo indiscutible del injusto la lesión de la voluntad general objetiva descrita en la norma, lo que a su vez conlleva la lesión de los intereses generales que constituyen dicha voluntad general, es decir, la infracción del contenido de la antijuridicidad material del hecho (Molina Fernández, F., Antijuridicidad penal y sistema del delito, Bosch, Barcelona, 2001, pp. 290-292).

${ }^{7}$ La ubicación de la imputabilidad no es pacífica. Hoy hay cierta coincidencia sobre su ubicación en la culpabilidad. En la evolución de la teoría del delito, podemos sostener que para los hegelianos, cuya sistemática iba de lo subjetivo a lo objetivo (del autor al acto), la imputabilidad era el primer componente de la teoría del delito. El loco no podía actuar con relevancia penal y la imputabilidad se confundía con la total capacidad psíquica de delito. Para la teoría psicológica de la culpabilidad (von Liszt), la imputabilidad era un presupuesto de la culpabilidad y la definían como la capacidad de motivación normal. Sin ella no podía tener relevancia penal la relación psíquica entre la conducta y el resultado y, como el dolo y la culpa eran formas de su culpabilidad descriptiva, no podía saberse por el injusto de qué delito imponían una medida de seguridad a un inimputable. Para algunos psicologistas como Lilienthal, la ubicación de la imputabilidad correspondía a la teoría de la responsabilidad. En la teoría compleja de la culpabilidad normativa, la tendencia mayoritaria consideraba que la imputabilidad era capacidad y elemento de la culpabilidad (Mezger); (b) la minoritaria consideraba a la imputabilidad como un presupuesto de la culpabilidad, lo que ofrecía los mismos inconvenientes que la teoría psicológica. El funcionalismo de Jakobs, al sostener un concepto de culpabilidad sin datos psicológicos, reducido a la necesidad de prevención general positiva, deduce que las 
sujeto desconoce el contenido de la norma o bien cuando pese a conocerlo el sujeto ha obrado en una situación de disculpa.

Así las cosas, de seguir este punto de vista hasta sus últimas consecuencias, me parece que los límites entre la antijuridicidad y la culpabilidad tienden debilitarse y no quedaría más remedio que aceptar que para obrar antijurídicamente, el sujeto debe obrar culpablemente, como lo sostiene la teoría del injusto culpable.

\section{Subjetivización Del injusto}

A juzgar por los hechos, un posible avance hacia la teoría del injusto culpable se condice con la manera en que se ha desarrollado la evolución de la dogmática penal. En efecto, una vez sentado el concepto de tipo por Beling en 1906 y completándose con ello la estructura clásica de la teoría del delito como acción, típica, antijurídica y culpable, la propia escuela clásica aceptaba que la acción (humana) debía estar dotada de voluntariedad, ${ }^{8}$ reconociéndose con ello un primer nivel de imputación. La referencia a la necesidad de una acción humana fue necesaria para la posición del injusto objetivo, para superar la crítica de Merkel acorde con la cual un concepto de antijuridicidad puramente objetivo debería extender su radio de acción a cualquier acontecimiento que provocara un estado de cosas desvalorado, incluyendo los acontecimientos naturales. Sin embargo, autores como Loffler llegaron a sostener esta conclusión, la cual resulta muy coherente con la idea de injusto objetivo centrado en el desvalor del resultado, pero extrema e inconveniente, toda vez que sumada a los problemas que generaba la teoría de la causalidad, entendían la antijuridicidad a niveles inadmisibles. Así, por ejemplo, Beling define la acción como un movimiento corporal (fase externa u objetiva de la acción) producido por el dominio sobre el cuerpo (libertad de inervación muscular voluntaria, correspondiente a la fase interna o subjetiva de la acción). Así, para este autor, la acción

ciencias psicológicas y sociales no pueden aportar nada al concepto de culpabilidad y que la inimputabilidad no es más que la falta de competencia para cuestionar la validez de la norma. Esta es una solución análoga a la del hegelianismo, que descalifica directamente al incapaz psíquico y ni siquiera lo considera capaz de acción o conducta. Esta perspectiva desarrollada coherentemente debiera concluir en que la inculpabilidad no depende de la incapacidad, sino de que la gente perciba como incapaz a alguien. Si alguien -por más loco que esté- no es considerado de ese modo por la gente, la vigencia de la norma (en este sentido) se debilita cuando aquél la infringe. De allí que debiera concluirse que inculpable no es el incapaz psíquico, sino el que la gente reconoce como tal. Pero también, inversamente, habrá que concluir: cuando un sujeto es percibido como loco por la opinión pública, habrá que considerarlo inimputable, porque todo poder punitivo será innecesario en ese caso para ratificar la validez de la norma. Aunque tampoco se lo dice, cabe entender que el reforzamiento de la confianza en el sistema demandará en ese caso el control psiquiátrico de quien no es incapaz. Esto llevaría directamente a la psiquiatrización de disidentes. Desde una perspectiva que puede considerarse diametralmente opuesta a la del funcionalismo, se considera a la inimputabilidad como algo diferente de una incapacidad, o sea, como una disidencia valorativa grupal o criterio político (Bustos Ramírez). Esta posición se funda en la crítica a la psiquiatría tradicional, sosteniendo el mero carácter político del límite de imputabilidad (Zaffaroni, E. R., Manual de Derecho Penal, Parte General, Ediar, Buenos Aires, 2006, pp. 542-551).

${ }^{8}$ Molina Fernández, F., ob. cit., pp. 213-219. 
consiste en un comportamiento corporal voluntario, consistente ya en un hacer (acción positiva), esto es, un movimiento corporal, por ejemplo levantar la mano, movimientos para hablar, etc., o bien en un no hacer (omisión), lo cual, para Beling, dice relación con la distensión de los músculos. ${ }^{9}$

Luego, fundamentalmente en la década del veinte, la escuela neokantiana reinterpretó en términos valorativos el concepto de acción como comportamiento, que fue entendido como materialización en el mundo exterior de la eficacia de la conducta humana. De acuerdo con ello la acción debía ser "comportamiento de la voluntad" (Hippel), "realización de la voluntad" (Mayer), "comportamiento arbitrario" (Rittler) o, sencillamente, "conducta bumana" (Mezger) que provoca un efecto en el mundo exterior (esta última parte extraída del concepto causal de acción). ${ }^{10}$

Además, fue el propio neokantismo el que aceptó que en el tipo penal había elementos subjetivos especiales, como el ánimo de lucro, que debían ya analizarse en el tipo. Hegler se percató de que el tipo comprende, además de los elementos objetivos, los elementos subjetivos que no son el dolo y la culpa, que se encuentran mencionados expresamente por el legislador, los cuales obligan a hacerse cargo en el análisis del tipo de los estados de ánimo del autor, sin que pueda trasladarse dicho análisis a la teoría de la culpabilidad. ${ }^{11}$

A continuación, la teoría finalista de Welzel dotó de intención a la categoría de la acción. Para Welzel la acción humana es el ejercicio de una actividad final es un acontecer final y no meramente causal. La finalidad u objetivo de la acción se basa en que el hombre, gracias a su saber causal, puede prever, dentro de ciertos límites, las consecuencias posibles de su actividad, y plantearse, por lo tanto, distintos fines u objetivos, y dirigir su actividad, conforme a su plan, a la consecución de estos fines. Por ello, Welzel afirmaba que la causalidad es ciega y, en cambio, la finalidad es vidente. ${ }^{12}$ Llama la atención la cercanía del concepto de acción final defendido por Welzel y Armin Kaufmann y el concepto sostenido por Binding, quien, heredero de la escuela hegeliana, postulaba que para que exista una acción en sentido jurídico debían concurrir tres elementos: $1^{\circ}$ un hecho entendido como una modificación de la realidad en el ámbito jurídico; $2^{\circ}$ dicha modificación debe corresponderse con una voluntad jurídicamente relevante, es decir, que la persona haya querido causar dicha modificación, y $3^{\circ}$ debe existir una relación causal entre la voluntad y el hecho; la voluntad humana debe haber sido la causa de dicho acontecimiento (imputación jurídica). Como puede advertirse, estos autores otorgan importancia a la finalidad perseguida por el autor como elemento de la acción humana, pero, a diferencia de la tesis finalista, Binding exige el conocimiento de la antijuridicidad y la imputabilidad ya en la acción. ${ }^{13}$

\footnotetext{
${ }^{9}$ Beling, E. V., ob. cit., pp. 19 y 20.

${ }^{10}$ Jescheck y Weigend, Tratado de Derecho penal, Comares, Granada, 2002, pp. 220-221.

${ }^{11}$ Roxin C., ob. cit., p. 280.

12 Welzel, H., Derecho penal alemán, Editorial Jurídica de Chile, Santiago, 2002, pp. 39-42.

${ }^{13}$ Molina Fernández, F., ob. cit., pp. 303-304.
} 
Luego, y como consecuencia de la estructura lógico objetiva de la acción final, Welzel traslada el dolo como dolo natural o avalorado desde la culpabilidad hacia el tipo subjetivo, estableciéndose en esta categoría un segundo nivel de imputación subjetiva. En este sentido, Welzel sostenía que las acciones finalistas, cuya voluntad de concreción está dirigida hacia la realización de resultados socialmente negativos, son calificadas de antijurídicas por el Derecho penal en los tipos de los delitos dolosos, tales como el asesinato, el homicidio, el hurto, etc., en los cuales el dolo, como concepto jurídico, es aquella voluntad finalista de la acción que está dirigida hacia la concreción de las características objetivas de un tipo de injusto. ${ }^{14}$

Si bien en la actualidad la ubicación del dolo y de la imprudencia en el tipo subjetivo se ha mantenido, ello ha ocurrido por razones de orden normativo y, por lo tanto, distintas a las esgrimidas por Welzel. Así, por ejemplo, para Roxin la pertenencia del dolo al tipo subjetivo tiene a su favor razones contundentes: $1^{\circ}$ ) Si el tipo debe tipificar el contenido de merecimiento de pena del correspondiente delito, no se puede renunciar al dolo para perfilar el tipo delictivo. Unos daños dolosos son algo sustancialmente distinto que los daños imprudentes. $2^{\circ}$ ) La tentativa de realizar un tipo sólo se puede juzgar si se tiene en cuenta el dolo del agente. Si en el delito intentado el dolo pertenece al tipo, entonces no convence que en el delito consumado sólo sea relevante desde el punto de vista de la culpabilidad, por cuanto la tentativa sólo se distingue de la consumación por la falta del resultado. $3^{\circ}$ ) La mayor parte de las acciones típicas son descritas por el legislador mediante verbos concebidos de modo final. $4^{\circ}$ ) Los elementos subjetivos del tipo no contenidos en descripciones objetivas de la acción típica presuponen el dolo y lo que es presupuesto necesario de un elemento del tipo, también ha de pertenecer como tal al tipo. ${ }^{15}$

Continuando con la subjetivización del injusto penal, la ciencia penal reconoce que no basta la sola concurrencia externa de las causales de justificación, sino que se debe atender además a la finalidad del sujeto, lo cual implica reconocer la necesidad de un elemento subjetivo en las causales de justificación. De esta forma, el injusto penal sigue siendo un juicio de desvalor de la conducta, pero no solo de su parte externa, fenoménica, sino considerada integralmente. El juicio de desvalor frente al ordenamiento jurídico se refiere tanto al comportamiento externo como a la finalidad del sujeto (elemento subjetivo). Por ello se habla de injusto personal, porque el comportamiento es contrario a derecho en relación a un autor determinado, es antijurídico para aquel que ejecutó el acto con una voluntariedad particular. El mismo hecho realizado por otro con una finalidad distinta podría estar justificado, de modo que la antijuridicidad es personal. Cuando un individuo quiere matar a otro y, al encontrarlo en un lugar solitario, lleva a efecto su designio, realiza una conducta antijurídica a pesar de que en la materialidad, considerando ese actuar con un criterio objetivo, podría darse una situación de defensa personal, porque la víctima estaba esperándolo allí precisamente para ultimarlo, y había iniciado la

${ }^{14}$ Welzel, H., Teoría de la acción finalista, Editorial Astrea, Buenos Aires, 1951, p. 27.

${ }^{15}$ Roxin, C., ob. cit., pp. 308-309. 
acción cuando el victimario disparó primero, ignorando tal circunstancia. Conforme a la doctrina clásica, el comportamiento sería jurídico, por cuanto objetivamente se obró en legítima defensa; para los finalistas, antijurídico, por cuanto se analiza el comportamiento en forma unitaria, donde lo objetivo y lo subjetivo se valoran como un todo. En la hipótesis el sujeto no se defiende quiere matar, así la antijuridicidad comprende tanto el desvalor del resultado como el desvalor del acto, y la tipicidad vuelve a ser ratio cognoscendi de la antijuridicidad. ${ }^{16}$

Por su parte, una vez trasladados al injusto el dolo y la imprudencia, la conciencia de la ilicitud se mantiene en el modelo welzelniano en la categoría de la culpabilidad, la cual constituye el tercer nivel de imputación subjetiva.

De lo dicho hasta aquí, es evidente que la evolución de la teoría del delito en los últimos cien años ha consistido claramente en enriquecer cada vez más a la antijuridicidad de elementos subjetivos, con lo cual una evolución hacia el injusto culpable no sería para nada una sorpresa.

\section{Normativización DEL injusto}

Por otro lado, es evidente que el definir la antijuridicidad como la contrariedad con el derecho obedece a una postura eminentemente normativa, lo cual se condice con la evolución de la dogmática penal, la cual ha tendido cada vez más a la normativización de sus categorías.

Con el devenir de la escuela neokantiana la acción causal se redefinió de manera normativa y, en el campo de la tipicidad, se aceptaron los elementos normativos del tipo. Max Ernst Mayer aceptó la existencia en el tipo de los elementos normativos del tipo, con lo cual el tipo deja de ser concebido como una categoría valorativamente neutra. El propio Mayer partía en principio del carácter no valorativo del tipo, ya que, según él, la realización del tipo ciertamente es un indicio de antijuridicidad (ratio cognoscendi de antijuridicidad), así el tipo se relaciona con la antijuridicidad como el humo con el fuego. El humo no es fuego, ni contiene fuego, pero permite extraer la conclusión de que hay fuego salvo prueba en contrario. Según Mayer, el tipo es solo ratio cognoscendi, o sea, un indicio denotador de antijuridicidad pero no es componente de la misma. Para él el carácter no valorativo del tipo está asegurado por el hecho de que los elementos del tipo son descriptivos, es decir, que contienen descripciones asequibles a la "percepción sensorial" (Ej: hombre, cosa, edificio), pero no contienen ya su valoración, que sólo se produce mediante la categoría de la antijuridicidad. La situación es distinta en los elementos normativos (o valorativos) del tipo, por cuanto son conceptos que no pueden captarse por la mera experiencia sensorial, como por ejemplo la ajenidad de la cosa en el delito de hurto, los cuales no describen objetos y por tanto tampoco están en relación causal con la acción del autor, sino que contienen

16 Garrido Montt, M., Derecho penal, parte general, Editorial Jurídica de Chile, Santiago, 2005, pp. 22-23. 
una valoración que en parte prejuzga la antijuridicidad, así el que sustrae una cosa ajena se inmiscuye en la propiedad de otro y en esa vulneración de la propiedad radica un elemento esencial del injusto de hurto. De ese modo, los elementos normativos del tipo son según él "auténticos elementos de la antijuridicidad. Puesto que una circunstancia que no señala la antijuridicidad, sino que la fundamenta, que no es, por consiguiente, ratio cognoscendi sino ratio essendi, pertenece a la antijuridicidad, es parte integrante de ésta. ${ }^{17}$ Pero, por otra parte, para Mayer esos elementos del tipo son impropios, porque la ley los convierte en objeto del dolo. Así, y porque el legislador los ubicó en esta posición, su particularidad sólo puede ser valorada dentro del concepto de tipo. De esta forma, los elementos normativos del tipo tienen, para Mayer, una doble posición: aparecen como si estuvieran fijadas con un gancho a la tipicidad y con otro a la antijuridicidad, tienen un doble carácter: son elementos normativos (y con ello inauténticos) de la tipicidad y son, a la vez, auténticos elementos de la antijuridicidad. ${ }^{18}$ En síntesis, podemos concluir que para Mayer excepcionalmente los tipos tienen elementos valorativos, los cuales son cuerpos extraños al tipo y que se encuentran ubicados en la descripción porque el legislador lo decidió, pero naturalmente pertenecen a la teoría de la antijuridicidad. De este modo, al admitir, de manera excepcional, elementos valorativos en la esfera del tipo penal, se había abandonado con ello la afirmación de la escuela positivista, consistente en que el tipo penal se caracterizaba por tener un carácter no valorativo. ${ }^{19}$

El descubrimiento de los elementos normativos del tipo se impuso rápidamente, poniéndose de manifiesto que el número de los elementos normativos era mucho mayor de lo que inicialmente se había supuesto. Así la clasificación que Mayer hacía en tipos normales, que eran aquellos que sólo contenían elementos descriptivos, y tipos anormales que, en cambio, eran aquellos que contenían o integraban elementos normativos o subjetivos, perdió sentido, toda vez que del solo recorrido por el Código penal resulta que, de seguir esta clasificación, los tipos anormales serían más que los tipos normales, por cuanto es frecuente que el legislador utilice elementos normativos para describir la conducta típica.

La evolución de la admisión de los elementos normativos en el tipo llegó a su punto culminante al probar Eric Wolf que incluso elementos presuntamente descriptivos puros, como "hombre" (ser humano) o "cosa" son normativos, al menos en sus ámbitos fronterizos, o sea, que requieren de una valoración judicial orientada a la antijuridicidad, y, en efecto, ello es correcto, ya que, por ejemplo, para determinar desde cuándo el sujeto adquiere la calidad de ser humano no nos basta con acudir a cuestiones meramente descriptivas, sino todo lo contrario, porque es la propia ley la que entrega ciertos elementos para determinar desde cuándo hay un ser humano; al sancionar el aborto, sin embargo, no establece límites claros, piénsese en la ardua discusión actual para determinar desde cuándo hay vida, surgiendo varias hipótesis cargadas de elementos valorativos (desde

\footnotetext{
${ }^{17}$ Mayer, M. E., Derecho penal, parte general, B de F, Buenos Aires, 2007, p. 231.

18 Mayer, M. E., ob. cit., p. 228.

${ }^{19}$ Roxin, C., ob. cit., pp. 281-282.
} 
la unión del óvulo con el espermatozoide, desde que el cigoto se anida en el cuello del útero, desde un plazo contado desde la anidación etc.). ${ }^{20}$ Desde este punto de vista, por lo tanto, el tipo aparece como una figura totalmente normativa, un "inseparable entramado estructural donde se entrelazan elementos de valor y elementos del ser". Pero de ello se deriva que de modo general ya no es posible seguir aferrándose al carácter no valorativo del tipo. Así, Mezger ya en 1926 sostuvo que la antijuridicidad o injusto (ve ambas expresiones como sinónimas) consiste en un juicio impersonal y objetivo sobre la contradicción existente entre el hecho y el ordenamiento jurídico en su conjunto, lo cual no excluye el hecho de que el Derecho penal a través del tipo destaque o delimite un campo especial del injusto al cual asocia una pena. De esta manera, Mezger concibe el tipo penal como tipo de injusto o, dicho de otra forma, como la antijuridicidad tipificada, aunque es cierto que no por sí sola, sino solo en unión con la falta de causas concretas de exclusión del injusto. Agrega Mezger que el tipo al describir el injusto adquiere una significación material, constituyendo el fundamento del injusto, constituyendo la ratio essendi del injusto y no mera ratio cognoscendi, como lo sostenía Mayer o Nagler. En consecuencia, cuando una conducta típica que se beneficia con una causa de exclusión del injusto no viene a convertir en legítima una situación antijurídica, sino que, en realidad, la conducta no es antijurídica desde un principio. ${ }^{21}$

De esta forma, Mezger, principal representante del neokantismo, a diferencia de Mayer, y partiendo de una concepción imperativa monista de las normas, niega autonomía a las normas permisivas. Las normas permisivas que subyacen a las causales de justificación sólo tienen sentido en referencia a un mandato o a una prohibición, sólo hay un permiso para hacer lo prohibido o lo ordenado, no hay un permiso independiente en sí mismo. Postula que la tipicidad es un juicio provisorio de antijuridicidad, esto es, es la ratio escendi de la antijuridicidad. Dice que la división entre tipicidad y antijuridicidad es antinatural, porque el legislador incorpora en el tipo todos los elementos de los cuales depende la ilicitud del delito. Por lo tanto, la tipicidad es un juicio provisorio de ilicitud, el juicio definitivo depende de si concurre o no alguna causal de justificación. Sostiene que las causales de justificación están en la parte general sólo por razones de economía legislativa para no repetirlas en cada tipo de la parte especial.

Esta teoría desemboca en la teoría de la tipicidad como juicio incondicional o definitivo de la ilicitud o teoría de las causales de justificación como elementos negativos del tipo, para la cual el legislador describe en el tipo los elementos en que se funda el injusto, esto es, los elementos descriptivos y, además, expresa que no concurran los elementos de una causal de justificación. Así, las causales de justificación y los elementos de hecho que las componen son elementos no expresados que forman parte del tipo, esto es, elementos negativos del tipo. Cada tipo especial sólo adquiere sentido cuando se vinculan sus elementos positivos y negativos en una unidad llamada tipo total. Ej.: el tipo total de homicidio consistiría en dar muerte a una persona, sin que concurran la legítima

\footnotetext{
${ }^{20}$ Roxin, C., ob. cit., p. 282.

${ }^{21}$ Mezger, E., Derecho penal, Tomo I, parte general, El Foro, Buenos Aires, 2001, pp. 131-162.
} 
defensa propia, de parientes, de terceros, calificada, etc. El tipo total de injusto contendría todos los elementos de la antijuridicidad llenándose de valoraciones. Hoy tiene varios adeptos esta teoría. ${ }^{22}$ Hay quienes la rechazan, pero aceptan sus efectos prácticos. ${ }^{23} \mathrm{Ej} .:$ Para la teoría finalista el dolo como elemento del tipo comprende el conocimiento de los elementos del tipo, más la voluntad de realización del objetivo, pero no comprende la conciencia de ilicitud, por lo tanto, si existe un error ante la creencia de que se actúa amparado en una causal de justificación que en realidad no concurre, o que no existe, o cuyos efectos se han extendido más allá de los casos señalados en la ley, habría para la teoría finalista un error de probibición que excluye, siguiendo a la teoría extrema de la culpabilidad, la culpabilidad, si es inevitable, y que puede atenuar la responsabilidad de ser evitable. En cambio para la teoría de las causales de justificación como elementos negativos del tipo habría un error de tipo, que de ser vencible excluye el dolo pero subsiste la culpa, y de ser invencible excluye el dolo y la culpa. Esta teoría del tipo como juicio provisional de injusto, que experimentó un impulso decisivo por parte del pensamiento referido al valor del neokantismo, sigue siendo dominante en un sector de la doctrina actual. Sin embargo, el reconocimiento de la normatividad del tipo ha dado lugar a que se plantee la cuestión de si realmente puede mantenerse la concepción del tipo como característica sistemática autónoma frente a la antijuridicidad. ${ }^{24}$

Welzel criticando la teoría de los elementos negativos del tipo señala que daría lo mismo matar a un mosquito que matar a un sujeto en legítima defensa, a lo cual los

22 Así por ejemplo, Luzón Peña, D., Curso de Derecho penal, parte general, Universitaria, Madrid, 2002, pp. 329 y ss.; Gómez de la Torre, B., Curso de Derecho penal, parte general, Experiencia, Barcelona, 2004, pp. 21 y ss. etc.

${ }^{23}$ Así, Mir Puig sostiene que: "El tipo reúne los elementos específicos que fundamentan positivamente la antijuridicidad penal de un hecho. Al hacerlo describe el comportamiento penalmente relevante. Además de su significado de presupuesto fundamentador de la antijuridicidad encierra, pues, un significado valorativo propio. Los hechos típicos no son "valorativamente neutros", sino penalmente relevantes. Esta relevancia no procede de que el hecho típico sea "antinormativo" e infrinja la prohibición de la norma (como quiere Welzel), sino que supone una lesión opuesta en peligro de un bien jurídico valioso para el Derecho penal. Las causas de justificación impiden considerar globalmente desvalorado el hecho típico realizado bajo su amparo, pero, en cambio, es evidente que no pueden hacer desaparecer la lesión o puesta en peligro del bien jurídico típico (que en sí mismo, aisladamente considerado, puede verse como un "mal”). Por otra parte, en cuanto tipo penal, llamado a seleccionar los hechos penalmente relevantes, el mismo contiene no sólo los elementos que fundamentan positivamente el injusto, sino también los que condicionan su "punibilidad". Este planteamiento supone rechazar el sentido amplio que da a la palabra "tipo" la llamada "teoría de los elementos negativos del tipo". Sin embargo, esta doctrina ha puesto de manifiesto algo que es correcto: el supuesto de becho antijurídico constituye una unidad con dos partes, una positiva (para nosotros el tipo) y otra negativa (la ausencia de los presupuestos de la situación justificada). El tipo no agota la descripción del supuesto de hecho antijurídico. Sí cabe decir, pues, que las causas de justificación son "elementos negativos del supuesto de hecho". La parte positiva del supuesto de hecho equivaldría al "tipo", en el sentido aquí acogido de lo "típico" de la figura de delito correspondiente; la parte negativa supondría la ausencia de causas de justificación. En este sentido, también puede hablarse de "tipo positivo" para referirse al "tipo" fundamentador del injusto, y de "tipo negativo" para designar el conjunto de presupuestos específicos ("típicos”) de cada causa de justificación. Pero aquí "tipo positivo" y "tipo negativo" no significarían "parte positiva y negativa del tipo", sino "parte positiva y negativa del supuesto de hecho”. Mir Puig, S. ob. cit. 164-165.

${ }^{24}$ Roxin, C., ob. cit., p. 283. 
partidarios de la teoría de los elementos negativos del tipo responden que lo importante es que ambos casos no quedan cubiertos por la menor sombra de desaprobación jurídica.

Luego, en el campo del nexo causal, se limitó la causalidad con criterios normativos tales como la teoría de la acción social y modernamente con la llamada teoría de la imputación objetiva o con la adopción del criterio del hombre medio ex ante. ${ }^{25}$

En la categoría de la culpabilidad, la escuela neokantiana percibió que la concepción psicológica fracasaba en la culpa inconsciente y con los aportes de Goldschmidt, Freudenthal y principalmente de Frank optó por la teoría normativa de la culpabilidad.

Reinhard Frank concibió la culpabilidad como un juicio de reprochabilidad de carácter normativo, acorde con el cual, para que pueda imputarse a un sujeto culpabilidad por la realización de la conducta prohibida, es necesario que este haya actuado dolosa o culpablemente y que las circunstancias concomitantes que rodean al hecho hayan sido normales. Sostiene Frank que la culpabilidad es un juicio de reproche dirigido al autor del hecho ilícito, porque habiendo estado en situación de conformar su conducta a los mandatos del derecho (podía y le era exigible) prefirió obrar en contra del derecho. Por lo tanto, para Frank, la culpabilidad es la reprochabilidad de una conducta típica y antijurídica según libertad, fin y significado conocido o conocible. ${ }^{26}$

James Goldschmidt se pregunta cuál es el carácter de la norma que sirve de base al juicio de culpabilidad y sostiene que al lado de cada norma jurídica que exige un comportamiento exterior conforme a derecho, y dice relación, por su carácter objetivo y general, con el injusto, hay una norma de deber que se dirige al individuo y le exige que "internamente" esté en condiciones de dar cumplimiento a las exigencias que le impone el orden jurídico. ${ }^{27}$ Esta segunda norma concierne, según Goldschmidt, a la culpabilidad. El fundamento normativo de la culpabilidad residiría en la violación de esta norma de deber. De esta forma, la culpabilidad llevaría ínsito un ingrediente normativo, constituido por la norma de deber que impone la obligación de motivarse en la dirección que manda la norma jurídica. No obstante ello, la violación de la norma de deber no conduce, sin embargo, al reproche de culpabilidad, si del individuo no podía exigirse su cumplimiento. ${ }^{28}$ La culpabilidad es un juicio de reproche que se formula al autor de una conducta, por no haber motivado su voluntad ante la representación de la norma de deber, siempre y cuando concurra la exigibilidad, es decir, el deber de motivación ante la representación del deber, presupone un poder hacerlo. Una motivación anormal o la falta de libertad del sujeto conducen a la no exigibilidad y, por ende, a la exculpación. Así cobra individualidad como causa de inculpabilidad la no exigibilidad de otra conducta, la cual es una de las herramientas básicas del normativismo. ${ }^{29}$ Las ideas de Goldschmidt tuvieron importancia para llegar a concluir que la actuación en un estado de necesidad

\footnotetext{
${ }^{25}$ Un mayor desarrollo de esta materia véase en el acápite número 7.

${ }^{26}$ Frank, R., Sobre la estructura del concepto de culpabilidad, B de F, Buenos Aires, 2004. pp. 19-37.

${ }^{27}$ Goldschmidt J., La concepción normativa de la culpabilidad, B de F, Buenos Aires, 2002, pp. 75-91.

28 Politoff Lifschitz, S., Derecho penal, Tomo I, LexisNexis, Santiago, 2001, pp. 322-323.

29 Novoa Monreal, E., Curso de Derecho penal chileno, Editorial Jurídica de Chile, Santiago, 2005,
} pp. 212-213. 
exculpante, previsto en el Código Penal alemán de la época, no afectaba en absoluto el juicio de antijuridicidad y que el sujeto que actúa dolosamente, en un estado de necesidad, puede, aun así, invocar la exclusión de la culpabilidad. ${ }^{30}$

Por su parte, Berthold Freudenthal sostuvo que para el hombre común el Derecho penal se ha vuelto inaccesible. Afirma que la opinión pública considera insoportable la condena del inocente; sin embargo, los penalistas no se detienen a ver si los conceptos de dolo y culpa concuerdan con las concepciones de la opinión pública. Agrega que en más de una ocasión se declara culpable al que, en lenguaje del lego, "nada podía hacer en lo sucedido, y ha obrado como cualquiera habría hecho en su lugar", no obstante, el recelo o el respeto por la especialidad es tan grande que nadie osa cuestionar sus categorías, lo cual ahonda el abismo entre el pueblo y el derecho. ${ }^{31}$ Señala que el legislador define el dolo como el conocimiento y la voluntad de los elementos del delito; sin embargo, el sujeto pudo haber realizado el supuesto de hecho referido en la norma consciente y voluntariamente, sin que se hubiese podido esperar de él, según las circunstancias, algo distinto que ese hecho, siendo el sujeto culpable para el jurista e inocente para el pueblo. Refiere que la jurisprudencia morigera esta situación en la determinación de la pena, pero ello no es suficiente. Dice que si bien el estado de necesidad exculpante permite una absolución para un reducido número de casos, tampoco hay aquí una solución adecuada. Por ello, sostiene que la solución sólo puede estar en la formulación del concepto de la culpabilidad, entendida como la reprochabilidad de la conducta antijurídica que se dirige al sujeto que habiéndose representado el resultado ha debido y podido obrar de otra manera, por cuanto el derecho reclama la subordinación de las decisiones de los sujetos a las regulaciones valorativas por él establecidas, siempre y cuando ello fuere posible, ya que la imposibilidad excluye la reprochabilidad jurídica. Postula que la exigibilidad de una conducta conforme a derecho debe entenderse como un elemento ético común al dolo y a la culpa, que constituye una exigencia jurídica para afirmar la existencia de la culpabilidad. ${ }^{32}$ Así, deberá negarse el reproche y con ello la culpabilidad cuando, en consideración a las circunstancias que rodearon al hecho, no es posible exigir al autor una conducta distinta, adecuada a la norma. 33

En la actualidad mientras para un sector de la doctrina, entre los cuales se encuentra a Jescheck y Hirsch, el fundamento de la culpabilidad sigue estando en la libertad del hombre, para el otro sector, liderado, principalmente por Roxin y Jakobs, el fundamento filosófico de la culpabilidad está en la prevención general. ${ }^{34}$

\footnotetext{
${ }^{30}$ Maurach y Zipf, Derecho penal, parte general, Editorial Astrea, Buenos Aires, 1994, p. 521.

${ }^{31}$ Freudenthal B., Culpabilidad y reproche en el Derecho penal, B de F, Buenos Aires, 2003, pp. 63-64.

32 Politoff Lifschitz, S., ob. cit., p. 324.

${ }^{33}$ Se alude aquí a la teoría normativa compleja, por cuanto todavía incluye en su seno al dolo y la culpa. Dicha teoría evoluciona hacia la teoría normativa pura con Hans Welzel, quien traslada el dolo (como dolo natural) y la culpa al tipo subjetivo.

${ }^{34}$ Schünemann, B., Sobre el estado actual de la teoría de la culpabilidad, en Obras, Tomo I, Rubinzal Culzoni Editores, Buenos Aires, 2009, pp. 437-464.
} 
Así, Roxin habla de "responsabilidad" y al respecto señala que en esta categoría se trata de determinar si el sujeto que realizó una acción típicamente antijurídica merece la aplicación de una sanción penal. Los presupuestos de la responsabilidad jurídico-penal son, para Roxin, entre otros, la culpabilidad, entendida como capacidad para comprender el injusto de su actuar y de actuar conforme a esa comprensión (imputabilidad), ${ }^{35}$ la posibilidad de conocimiento de la antijuridicidad y la normalidad de la situación en la que se actúa (exigibilidad de otra conducta conforme a derecho). ${ }^{36}$ La responsabilidad depende de dos factores que deben añadirse al injusto y que son: la culpabilidad del sujeto y la necesidad preventiva (prevención general y especial) de la sanción penal, que hay que deducir de la ley. Para Roxin, a diferencia de Welzel, no interesa determinar si el sujeto podía actuar de otro modo, sino si es o no necesaria la pena.

Para Jakobs (al igual que para Roxin), ${ }^{37}$ es irrelevante el problema de la libertad. ${ }^{38}$ La responsabilidad se establece con independencia de si el sujeto al momento de cometer el hecho estaba o no dotado de libertad, por cuanto se trata de un presupuesto que no es posible demostrar en el caso concreto. Lo importante es determinar si hay una alternativa de organización que sea preferible en general. El sujeto es libre no en el sentido del libre albedrío, sino en cuanto a la falta de obstáculos jurídicamente relevantes para sus actos de organización. ${ }^{39}$

En el tipo imprudente se aprecia con fuerza el proceso de normativización aceptando como núcleo de su estructura el elemento de la infracción del deber de cuidado. En tal sentido, Mir Puig refiere que la doctrina dominante en Alemania acepta en la actualidad el punto de partida de Engisch, desarrollado por Welzel, partiendo de la distinción de un aspecto objetivo normativo (infracción del objetivo deber de cuidado exigible en el tráfico) y un aspecto individual (poder individual del autor de observar el cuidado objetivamente debido y se incluye en la culpabilidad). ${ }^{40}$

Lo mismo sucede en el ámbito del delito omisivo en donde Silva Sánchez postula que la omisión surge en virtud de un juicio de imputación que se produce en el tipo y no de acción, ya que la omisión no consiste en no hacer nada, sino en no llevar a cabo una determinada conducta, por lo que el tipo penal se realiza si tiene lugar una conducta distinta a la prevista. Si en los delitos de acción existe la infracción de una norma prohibitiva, en los delitos de omisión se infringe una norma de carácter preceptiva, esto es, que obliga a una determinada cooperación deseable. ${ }^{41}$ En la omisión mediante el juicio de imputación que se realiza a nivel del tipo, se atribuye (imputa) a la conducta del sujeto la no realización de una prestación positiva estimada ex ante como necesaria para la

\footnotetext{
${ }^{35}$ Roxin, C., ob. cit., pp. 822-823.

${ }^{36}$ Roxin, C., ob. cit., p. 791.

${ }^{37}$ Roxin, C., ob. cit., pp. 799-800.

${ }^{38}$ Sobre el problema de la libertad como fundamento de la culpabilidad, ver Engisch, K., La teoría de la libertad de la voluntad en la actual doctrina filosófica del Derecho penal, Edeval, Valparaíso, 2006.

39 Jakobs, G., ob. cit., pp. 584 y ss.

${ }^{40}$ Mir Puig, S., ob. cit., p. 290.

${ }^{41}$ Mir Puig, S., ob. cit., pp. 308-309.
} 
salvaguarda de un bien jurídico (concepto material). Bases del juicio de imputación son, pues, la conducta efectiva del sujeto y la pretensión positiva y no sólo la negativa. ${ }^{42}$

\section{Desplazamiento del eje desde el Desvalor del resultado HACIA EL DESVALOR DEL ACTO}

Las posiciones que definen la antijuridicidad en torno a la afectación de los bienes jurídicos deben para ser coherentes, centrarse en el desvalor del resultado, lo cual genera una serie de inconvenientes, por cuanto un modelo centrado en el desvalor del resultado es más proclive a aceptar el versari in re illicita, los delitos calificados por el resultado y la responsabilidad objetiva, con una clara afectación del principio de culpabilidad.

En cambio, si lo que en verdad importa es la infracción de la norma más que el resultado mismo, debiese coherentemente asignarse más valor al desvalor del acto que al desvalor del resultado. En tal sentido, debe tenerse presente que esta ha sido la tendencia natural que se viene dando en la evolución de la teoría del delito, lo cual se aprecia primero en la necesidad de establecer en la tipicidad algún tipo de restricción a la causalidad a la hora de imputar un resultado a la conducta de un sujeto. En un primer momento la dogmática penal buscó la solución en las llamadas teorías individualizadoras, las cuales fracasaron porque intentaron limitar la causalidad en el plano meramente ontológico. Luego, la teoría de la imputación objetiva no demoró en ser ampliamente acogida por la dogmática penal, por encontrar en ella un remedio eficaz a los problemas derivados de la causalidad, no ya en el campo ontológico, sino que en un segundo nivel de análisis de carácter normativo. Así, los planteamientos provenientes del ámbito de Derecho civil y específicamente de Larenz fueron recogidos por Honing y encontraron su mayor desarrollo en el ámbito del Derecho penal mediante la formulación de criterios normativos por Roxin. Así, en los delitos de resultado no basta la concurrencia de la causalidad para afirmar la tipicidad objetiva del tipo, sino que debe concurrir además la creación de un riesgo desaprobado para el ordenamiento jurídico (desvalor de acto) y debe ser ese riesgo y no otro el que se materialice en el resultado lesivo (desvalor del resultado). Así, no concurrirá el desvalor del acto cuando la conducta disminuye el riesgo para el bien jurídico o bien cuando se trata de un riesgo socialmente adecuado. Por su parte, desaparecerá el desvalor del resultado cuando el riesgo creado se encuentra fuera del ámbito de protección de la norma, en los casos de autopuesta en riesgo de la víctima o bien en aquellos que dicen relación con la conducta alternativa adecuada a derecho. A estos criterios, Jakobs agrega el principio de confianza, la prohibición de regreso y la teoría de la concurrencia de los riesgos.

No obstante que inicialmente la teoría de la imputación objetiva tenía únicamente por finalidad la limitación de la causalidad, en la actualidad se ha convertido en una categoría de reformulación general de la tipicidad, la cual se basa en el examen de la

\footnotetext{
42 Silva Sánchez, J. M., El delito de omisión, concepto y sistema, Bosch, Barcelona, 1986, p. 158.
} 
acción desde la perspectiva de la idea de la peligrosidad objetiva ex ante del hecho para los bienes jurídicos. ${ }^{43}$ Acorde con la teoría de la imputación objetiva un resultado causado por el agente sólo se puede imputar al tipo objetivo si la conducta del autor ha creado un peligro para el bien jurídico no cubierto por un riesgo permitido y ese peligro también se ha realizado en el resultado concreto. ${ }^{44}$ Además, podemos señalar que en la actualidad la atención se desplaza también desde la óptica de la imputación objetiva hacia el desvalor del acto. En tal sentido, Wolfgang Frisch pone de manifiesto la importancia del desvalor del comportamiento, refiriendo que tan sólo pueden desaprobarse jurídicamente aquellas conductas que comporten riesgos especiales de producción de lesiones típicas. Estos riesgos especiales se determinan a causa de la concurrencia de ciertas circunstancias en torno a la posibilidad de producción del daño. Allí donde tales riesgos existen sin una razón que legitime la desaprobación de la conducta (riesgos mínimos aceptables en virtud del desarrollo o que se realizan sólo en caso de una conducta errónea de un tercero racional, etc...), estas conductas no son, de ningún modo, idóneas para la fundamentación del injusto (de la acción), objetivo requerido por los tipos consumados. Lo anterior tiene relevancia en el ámbito de la tentativa, por cuanto no se puede considerar ilícita la creación consciente de riesgos tolerados, por mucho que vayan acompañados de malas intenciones. ${ }^{45}$ Tanto en el tipo doloso como en el tipo imprudente, cuyo núcleo consiste en la infracción objetiva de un deber de cuidado, la teoría de la imputación objetiva se ha convertido en una categoría de reformulación general de la tipicidad, basada en el examen de la acción desde la perspectiva de la peligrosidad objetiva ex ante del hecho para bienes jurídicos.

En segundo lugar, el creciente aumento en la consideración del desvalor del acto se aprecia en la necesidad creciente de adoptar una perspectiva ex ante en el examen de algunas causas de justificación y sobre todo en aquellas relacionadas con el cumplimiento de deberes jurídicos, lo cual se fundamenta en la necesidad de fomentar la libertad de acción y en la de poder saber en el momento de actuar si el hecho es o no correcto, ya que lo contrario sería inadecuado al injusto.

En tercer lugar, la consideración del desvalor del acto se aprecia en el afianzamiento de la idea de que la infracción del deber de cuidado es un elemento propio de la antijuridicidad en el tipo imprudente y, por último, en la fundamentación del contenido del injusto en el desvalor de la acción entendido como desvalor de peligro, en los delitos sin resultado lesivo, como los actos preparatorios punibles, la tentativa o los delitos de mera actividad y de peligro. En efecto, parte de la doctrina está de acuerdo en exigir el requisito normativo de la imputación objetiva de la conducta en los delitos de mera actividad y

\footnotetext{
${ }^{43}$ Molina Fernández, F., ob. cit., pp. 375-380.

${ }^{44}$ Roxin, C., ob. cit., p. 363.

${ }^{45}$ Frisch y Robles, Desvalorar e imputar, sobre la imputación objetiva en Derecho penal, Atelier, Barcelona, 2004, p. 43, y Frisch, W., Comportamiento típico e imputación del resultado, Marcial Pons, Barcelona, 2004,
} p. 61 . 
de peligro para poder atribuir responsabilidad penal al sujeto activo. ${ }^{46}$ En efecto, si bien en esta clase de delitos no resulta necesario probar un resultado determinado separado de la conducta, ni mucho menos un nexo entre la conducta y dicho resultado, como ocurre en los delitos de lesión o de daño como el homicidio o las lesiones, ello no exime de la obligación de acreditar, conforme al principio nulla poena sine iniura o de lesividad, que la conducta desplegada por el sujeto activo constituye ex ante un riesgo normativo típicamente relevante para el objeto de tutela. De ahí que Mir Puig sostenga que en ciertos tipos penales, como los de mera actividad, pueda faltar la causalidad, pero que en ningún caso puede estar ausente la imputación objetiva, al menos de la conducta.

\section{Algunas posibles Consecuencias de aCePtar la idea} DEL INJUSTO CULPABLE

1. En materia de autoría y participación la doctrina mayoritaria defiende el principio de la accesoriedad media, es decir, para que el partícipe responda penalmente es necesario que el autor haya realizado al menos una acción típica y antijurídica. Siendo coherentes con la postura antes referida, si aceptamos que para obrar antijurídicamente debe necesariamente el sujeto haber obrado culpablemente, entonces lo lógico es que para hacer responsable al partícipe sostuviéramos el principio de la accesoriedad máxima, es decir, para que sea posible hacer responsable al partícipe el autor debería haber realizado una acción típica, antijurídica y culpable.

2. Cabría tomar como base del sistema la tentativa acabada, por cuanto en ella se dan todos los elementos de la infracción de la norma. En cambio, la postura tradicional, al fundar la antijuridicidad en la afectación de bienes jurídicos, toma como base el delito consumado, de lo cual surgen problemas para fundar la tentativa y los actos preparatorios, en los cuales no hay lesión, por lo tanto debe recurrir a la idea de peligro para bienes jurídicos, lo que entraña la necesidad de ampliar el concepto de antijuridicidad introduciendo el concepto de peligro, lo cual tiene la dificultad de que es imposible identificar la idea de peligro con la de lesión. La alternativa consiste en subjetivizar el concepto de injusto y tomar como modelo el delito intentado y tomar el desvalor subjetivo de la acción como centro del injusto; el resultado lesivo se extrae del injusto y se convierte en condición objetiva de punibilidad. Sin embargo, para esta teoría, es difícil argumentar en esta solución porque el delito tentado debiese tener menor pena que el delito consumado. Del mismo modo, tiene el inconveniente de que reduce o hace desaparecer el desvalor material, afectándose con ello el principio de lesividad, pilar del injusto no culpable.

3. Habría que sacar de la infracción de la norma el resultado y el resultado justificado. Si lo relevante es la infracción de la norma y ello ha sucedido, que el resultado se

${ }^{46}$ Al respecto, ver Mir Puig. S. ob. cit., p. 259; Torio López, "Naturaleza y ámbito de la teoría de la imputación objetiva", en Anuario de derecho penal y ciencias penales, Tomo 39, Fasc-Mes 1, 1986 , pp. 33-48, y Luzón Peña, D. Curso de Derecho penal, parte general, Universitas, Madrid, 1996, p. 387. 
haya o no producido depende un poco del azar. Así, en dos accidentes de tránsito y frente a unas lesiones de gravedad similar, es posible que al paciente del primer accidente le toque un médico espectacular, pero al paciente del segundo accidente, de iguales características que el primero, un médico recién titulado con la pericia media acorde a la lex artis. El paciente del primer accidente logra su recuperación en excelentes condiciones y en cambio el paciente del segundo accidente muere o queda con lesiones permanentes. En este caso, ¿qué, si no el azar marcó el destino de ambos pacientes? Si la infracción de la norma es la misma en ambos accidentes, ¿podemos decir que concurre un mayor merecimiento de pena en el sujeto activo del segundo accidente porque para su mala suerte a su víctima lo atendió un médico que cumpliendo los requisitos de la lex artis no era tan diestro como el médico del primer accidente?

4. Si bien pueden producirse situaciones jurídicamente desvaloradas y que provocan una reacción jurídica sin que medie un comportamiento culpable del sujeto, como ocurre con los sujetos a los cuales se les aplican medidas de seguridad, la verdad es que hay situaciones en las cuales es discutible siquiera si estamos en presencia de una acción, como por ejemplo un ataque de epilepsia. En otras situaciones como las llevadas a cabo por un inimputable la verdad es que parece contradictorio esperar a la culpabilidad para analizar la antijuridicidad del hecho, por cuanto el inimputable realizó el hecho desde un inicio con sus características personales que lo hacen inimputable. En consecuencia, pareciera ser que las medidas de seguridad requieren de una estructura propia de análisis que permita analizar el problema de manera más coherente.

\section{BIBLIOGRAFÍA}

Beling, E. V., Esquema de derecho penal, la doctrina del delito tipo, Depalma, Buenos Aires, 1944.

ENGISCH, K., La teoría de la libertad de la voluntad en la actual doctrina filosófica del derecho penal, Edeval, Valparaíso, 2006.

Feuerbach, A. V., Tratado de derecho penal, Hammurabi, Buenos Aires, 2007.

Frank, R., Sobre la estructura de la culpabilidad, editorial B de F, Buenos Aires, 2004.

Freudenthal, B., Culpabilidad y reproche en el derecho penal, editorial B de F, Buenos Aires, 2003.

Frisch y Robles, Desvalorar e imputar. Sobre la imputación objetiva en derecho penal, Editorial Atelier, Barcelona, 2004.

Frisch W., Comportamiento típico e imputación del resultado, Marcial Pons, Barcelona, 2004.

Garrido Montt, M., Derecho penal, parte general, Editorial Jurídica de Chile, Santiago, 2005.

Gómez de la Torre, B., Curso de derecho penal, parte general, experiencia, Barcelona, 2004.

Goldschmidt, J., La concepción normativa de la culpabilidad, editorial B de F, Buenos Aires, 2002

Jakoвs, G., Derecho penal, parte general. Fundamentos y teoría de la imputación, $2^{\text {a }}$ edición, Marcial Pons, Madrid, 1997.

Jescheck y Weigend, Tratado de derecho penal, parte general, $5^{\text {a }}$ edición, Editorial Comares, Granada, 2002.

Liszi, F. V., Tratado de derecho penal, Valletta ediciones, Buenos Aires, 2007.

LuZón PeÑA, D., Curso de derecho penal, parte general, Universitas, Madrid, 1996. 
Maurach y ZipfF, Derecho penal, parte general, traducción de la $7^{\mathrm{a}}$ edición, Editorial Astrea, Buenos Aires, 1995.

Mayer, M. E., Derecho penal, parte general, editorial B de F, Buenos Aires, 2007.

Mezger, E., Derecho penal, tomo I, parte general, El Foro, Buenos Aires, 2001.

Mir Puig, S., Derecho penal, parte general, $7^{\mathrm{a}}$ ed., editorial B de F, Montevideo - Buenos Aires, 2005.

Molina Fernández, Antijuridicidad penal y sistema del delito, Editorial Bosch, Barcelona, 2001.

Novoa Monreal, E., Curso de derecho penal chileno, parte general, $3^{\mathrm{a}}$ edición, Editorial Jurídica de Chile, Santiago, 2005.

Politoff Lifschitz, S., Derecho penal, tomo I, $2^{\text {a }}$ edición, Editorial Conosur, Lexis Nexis, Santiago de Chile, 2001.

Politoff, Matus y Ramírez, Lecciones de derecho penal chileno, parte general, Editorial Jurídica de Chile, Santiago, 2004.

Roxin, C., Derecho penal, parte general, fundamentos. La estructura de la teoría del delito, Editorial Civitas, Madrid, 2001.

Silva SÁnchez, J. M., El delito de omisión, concepto y sistema, Editorial Bosch, Barcelona, 1986.

Silva Sánchez, J. M., Aproximación al derecho penal contemporáneo, Bosch, Barcelona, 1992.

Schünemann, Sobre el estado actual de la teoría de la culpabilidad, en obras, tomo I, RubinzalCulzoni Editores, Buenos Aires, 2009.

Torio López, "Naturaleza y ámbito de la teoría de la imputación objetiva", en Anuario de derecho penal $y$ ciencias penales, tomo 39, fasc-mes 1, 1986, pp. 33-48.

Welzel, H., Derecho penal alemán, parte general, $4^{a}$ edición, Editorial Jurídica de Chile, Santiago, 2002.

Welzel, H., Teoría de la acción finalista, Editorial Astrea, Buenos Aires, 1951.

Zaffaroni, E. R., Manual de derecho penal, parte general, Ediar, Buenos Aires, 2006. 
